\title{
Nasal cancers, symptoms and upper airway function in woodworkers
}

\author{
H. C. ANDERSEN, ${ }^{1}$ I. ANDERSEN, ${ }^{2}$ AND J. SOLGAARD ${ }^{2}$ \\ From the ${ }^{1}$ Department of Otorhinolaryngology, Community Hospital, Aarhus, and the ${ }^{2}$ Institute of Hygiene, \\ University of Aarhus, Denmark
}

ABSTRACT In 186 cases of nasal cancer diagnosed over the decade $1965-74$, in a population of $2 \cdot 0$ million, 114 of 157 ectodermal tumours were found in men. Adenocarcinoma was found in 17 patients, two women and 15 men; 12 of these had a history of occupational exposure to wood dust in the furniture industry. The period of latency was from 28 to 57 years. Among the remaining 99 tumours in men there was occupational exposure to wood dust in 10 cases. Wood dust concentrations in the breathing zone, respiratory symptoms and upper airway function were studied in 68 workers in the furniture industry. The dust concentrations affecting $63 \%$ of the workers were higher than $5 \mathrm{mg} / \mathrm{m}^{3}$ (TLV). Middle ear inflammation and common colds were more frequent at high dust concentrations, and the number of workers with nasal mucostasis was directly proportional to the wood dust concentration.

Nasal cancers are rare in the general population, but since 1967 it has been known (Acheson et al., 1967) that this disease is a substantial risk for woodworkers exposed to dust in the furniture industry, and that the predominant type is adenocarcinoma. A country-wide investigation in England and Wales and less comprehensive investigations in Belgium, France and Denmark have confirmed this (Debois, 1969; Gignoux and Bernard, 1969; Mosbech and Acheson, 1971; Acheson et al., 1972). Certain workers in the boot and shoe manufacturing industry also have an increased risk of nasal cancers (Acheson et al., 1970). In addition, a preliminary investigation has indicated that nasal mucociliary function is impaired in woodworkers (Black et al., 1974).

The purpose of this investigation was to study the incidence of nasal cancers of various histological types in relation to occupation, and to study airway symptoms, nasal mucociliary flow and airway resistance in woodworkers as well as dust levels in workrooms in the furniture industry.

Materials and methods

The study comprises an investigation of hospital

Reprint requests to: $\mathrm{Dr}$ I. Andersen, Hygiejnisk Institut, Universitetsparken, DK 8000 Århus C, Denmark.

Received for publication 7 March 1977

Accepted for publication 5 April 1977 case records, and field measurements in furniture industries.

\section{CASE RECORDS}

In the period 1965-74 in the ear, nose and throat department, Aarhus Community Hospital, Aarhus, 186 patients were treated for malignant or semimalignant tumours in the nose and paranasal sinuses. The treatment of these disorders is strictly centralised, and the catchment area comprises about 2.0 million inhabitants. Ectodermal tumours were found in 157 (114 men, 43 women) of the 186 patients and 29 ( 15 men, 14 women) had other types of tumour. As the latter group did not contain patients occupationally exposed to gases, vapours or dust, especially wood dust, this group has been omitted from the analysis. An investigation of death certificates with the diagnosis nasal cancer did not reveal further cases in the 10-year period investigated.

MEASUREMENTS IN THE FURNITURE INDUSTRY This part of our study comprised eight furniture industries in Aarhus county. The sample included only plants with more than 12 workers. In each plant workers on very dusty work such as sanding, and workers on processes with a low dust production such as veneering and assembling were investigated. However, the different processes were often carried out in the same room. Workers engaged in 
varnishing, painting or similar occupations, as well as those with a cold within the two weeks before the investigation, were excluded. In all, 68 workers were examined, all of whom were men between 17 and 66 years (mean 41 years). They had been employed in the furniture industry for one to 51 years (mean 16 years).

The study took place from November 1974 to January 1975 , a period with outdoor temperatures ranging from three to $10^{\circ} \mathrm{C}$. The investigation was always carried out in the afternoon, and was thus preceded by at least five hours' normal work. The workers were initially questioned about their present and former working conditions, airway symptoms and smoking habits. The mouth and nose were then inspected using a head lamp and speculae, a forced expiratory spirogram was obtained, and finally the nasal mucociliary clearance was measured with the saccharine/sky-blue technique(Andersen et al.,1974). A $0.5 \mathrm{~mm}$ blue-stained saccharine particle was placed on the superior surface of the inferior turbinate. The subjects then returned to their normal work and were instructed to report a sweet taste as soon as it was noted. Verification was obtained by the appearance of blue-coloured mucus in the oropharynx. The time of passage measured with a stop-watch was from the moment of placement to the arrival of blue mucus in the oropharynx.

The dust concentration was measured with a personal sampler (MSA model G) with a sampling head consisting of a filter holder (Sartorius SM 16517) and a filter (Sartorius SM 11304025) with a $0.8 \mu \mathrm{m}$ pore size, placed in the breathing zone of the worker. Similar measurements with a high volume sampler placed one metre from the place of work were also obtained, as well as temperature and humidity measurements. The filters were weighed after they had been acclimatised for 18 hours in the weighing room.

\section{Results}

Non-parametric tests have been used for the statistical calculations (Siegel, 1956). Our significance level was five per cent.

\section{CASE RECORDS}

Table 1 shows the histological type of the ectodermal tumours by site. It appears that $59 \%$ were situated in the nasal cavity, whereas 17 and $24 \%$ were in the vestibular part of the nose or in the maxillary sinus respectively. The most common tumour in the nasal cavity was the epithelial papilloma, the next common was the adenocarcinoma. In the latter group of 17 patients, 12 were woodworkers; the remaining five comprised two farmers, a grocer, a nurse, and a farmer's wife. The latter were the only two women. There were 22 woodworkers altogether, the remaining 10 having an even distribution of other tumour types, and all being male. Three of the tumours in the vestibule of the nose were found in woodworkers (two carpenters and one turner), and there were two woodworkers (one carpenter and one sawyer) with maxillary sinus tumours.

Table 2 gives the histological type of nasal cancers in woodworkers with different occupations. Adenocarcinoma was the most prevalent, and 10 out of 12 were found in cabinet and chair makers. The remaining 10 tumours were evenly distributed by type and worker's occupation.

Detailed information concerning occupational history was obtained from the 12 cabinet and chair makers with nasal adenocarcinoma; all had been working with several kinds of wood, primarily beech, oak and walnut but periodically also with mahogany and teak. The information was insufficient to allow quantification of the dust exposure. Nobody took snuff, and smoking was not allowed at work because of the fire risk.

Table 1 Histological type of ectodermal tumours in the nose by site

\begin{tabular}{|c|c|c|c|c|c|}
\hline \multirow[t]{2}{*}{ Type of ectodermal tumour } & \multicolumn{3}{|c|}{ Number of tumours in each site } & \multirow{2}{*}{$\begin{array}{l}\text { Total number } \\
\text { of workers }\end{array}$} & \multirow{2}{*}{$\begin{array}{l}\text { Woodworkers } \\
\text { only }\end{array}$} \\
\hline & $\begin{array}{l}\text { Vestibule of } \\
\text { the nose }\end{array}$ & Nasal cavity & Maxillary sinus & & \\
\hline Epithelial papilloma (Ewing) & & 33 & & 33 & 1 \\
\hline Epithelial carcinoma & 26 & 16 & 29 & 71 & 5 \\
\hline Adenocarcinoma & & 17 & & 17 & 12 \\
\hline Adenocystic carcinoma & & 4 & 5 & 9 & 1 \\
\hline Anaplastic carcinoma & 1 & 7 & 1 & 9 & $i$ \\
\hline Transitional cell carcinoma & & 3 & i & 4 & \\
\hline Malignant melanoma & & 13 & & 13 & 2 \\
\hline Malignant sialoma & & & 1 & 1 & \\
\hline All & 27 & 93 & 37 & 157 & 22 \\
\hline
\end{tabular}


Table 2 Relationship of work in the wood industry to histological type of ectodermal tumours in the nose

\begin{tabular}{|c|c|c|c|c|c|c|c|}
\hline \multirow[t]{2}{*}{ Occupation } & \multicolumn{6}{|c|}{ Number of workers with each type of tumour } & \multirow[t]{2}{*}{ Tota } \\
\hline & $\begin{array}{l}\text { Adeno- } \\
\text { carcinoma }\end{array}$ & $\begin{array}{l}\text { Adenocystic } \\
\text { carcinoma }\end{array}$ & $\begin{array}{l}\text { Anaplastic } \\
\text { carcinoma }\end{array}$ & $\begin{array}{l}\text { Malignant } \\
\text { melanoma }\end{array}$ & $\begin{array}{l}\text { Epithelial } \\
\text { carcinoma }\end{array}$ & $\begin{array}{l}\text { Epithelial } \\
\text { papilloma }\end{array}$ & \\
\hline $\begin{array}{l}\text { Cabinet and } \\
\text { chair makers }\end{array}$ & 10 & & 1 & 1 & & & 12 \\
\hline Carpenters & & 1 & & 1 & 1 & & 3 \\
\hline Turners & 1 & & & & 1 & & 2 \\
\hline Coach makers & 1 & & & & & & 1 \\
\hline Coopers & & & & & & 1 & 1 \\
\hline Sawyers & & & & & 1 & & 1 \\
\hline Forest workers & & & & & 1 & & 1 \\
\hline Brush makers & & & & & 1 & & i \\
\hline All woodworkers & 12 & 1 & 1 & 2 & 5 & 1 & 22 \\
\hline
\end{tabular}

The latent period, or time from entry into the furniture industry to the discovery of the tumours is shown in Figure 1, where the white columns represent the period of employment in the furniture industry. Eight workers were employed only in the furniture industry, whereas four subsequently took other jobs, three as carpenters and one as a tobacco dealer. In the first group the latent period was from 57 to 29 years (average 46 years) with a tendency to shorter latent periods in more recent years; in the second group the latent period was from 34 to 28 years (average 31 years). The shortest latent period was 28 years, in a patient who had been a coach- maker for 15 years, and then a tobacco dealer for 13 years.

\section{MEASUREMENTS IN WOOD INDUSTRIES}

The distribution of the dust levels measured with the personal sampler is shown in Figure 2. The threshold limit value for workroom air is $5 \mathrm{mg}$ wood dust per $\mathrm{m}^{3}$ air (American Conference of Governmental Industrial Hygienists, 1976) and it appears that $43(63 \%)$ of the 68 measurements were above that value. Nineteen measurements $(28 \%)$ were more than twice the TLV. The dust measurements with the stationary equipment gave almost identical
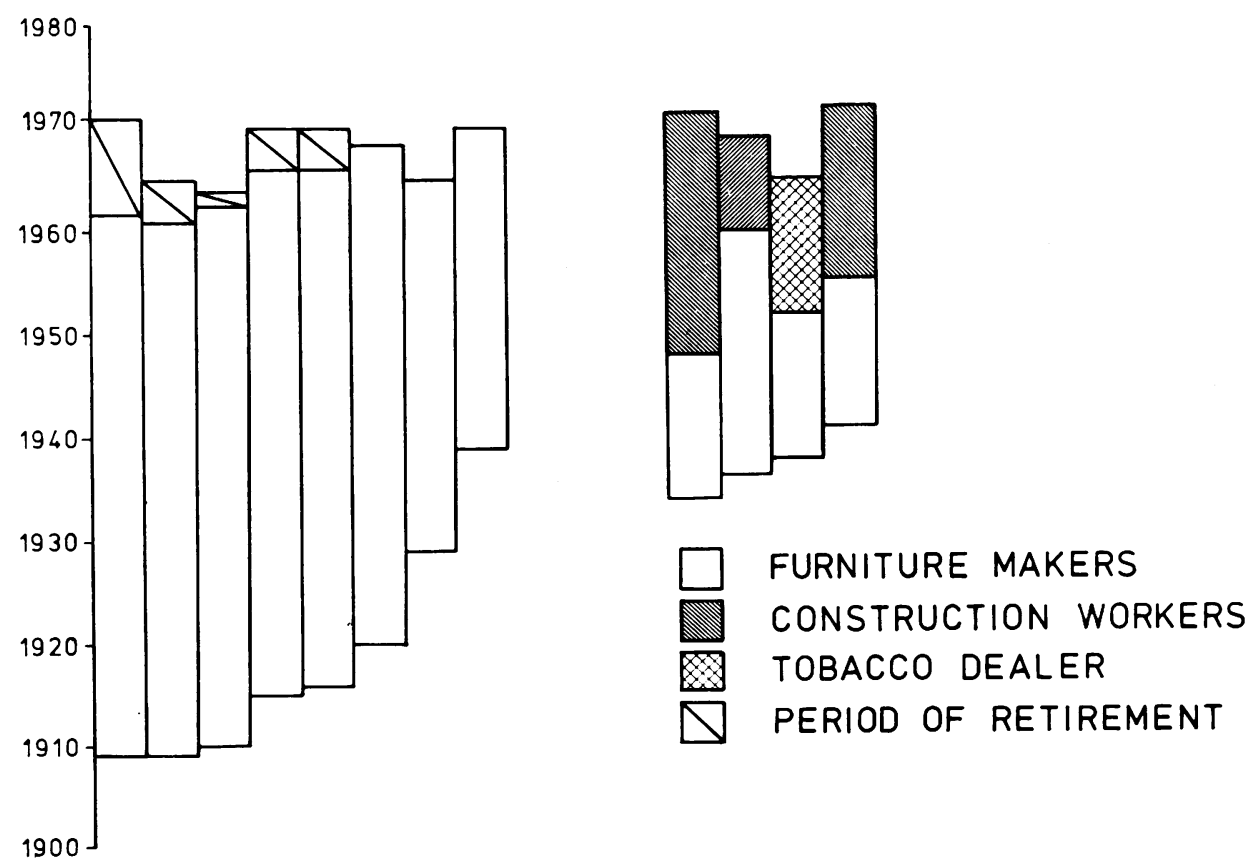

Fig. 1 Latent periods for the development of adenocarcinoma of the nose in 12 woodworkers in the furniture industry. The lower end of each bar represents the year of entry into the furniture industry, the upper end the year of discovery of the tumour. 


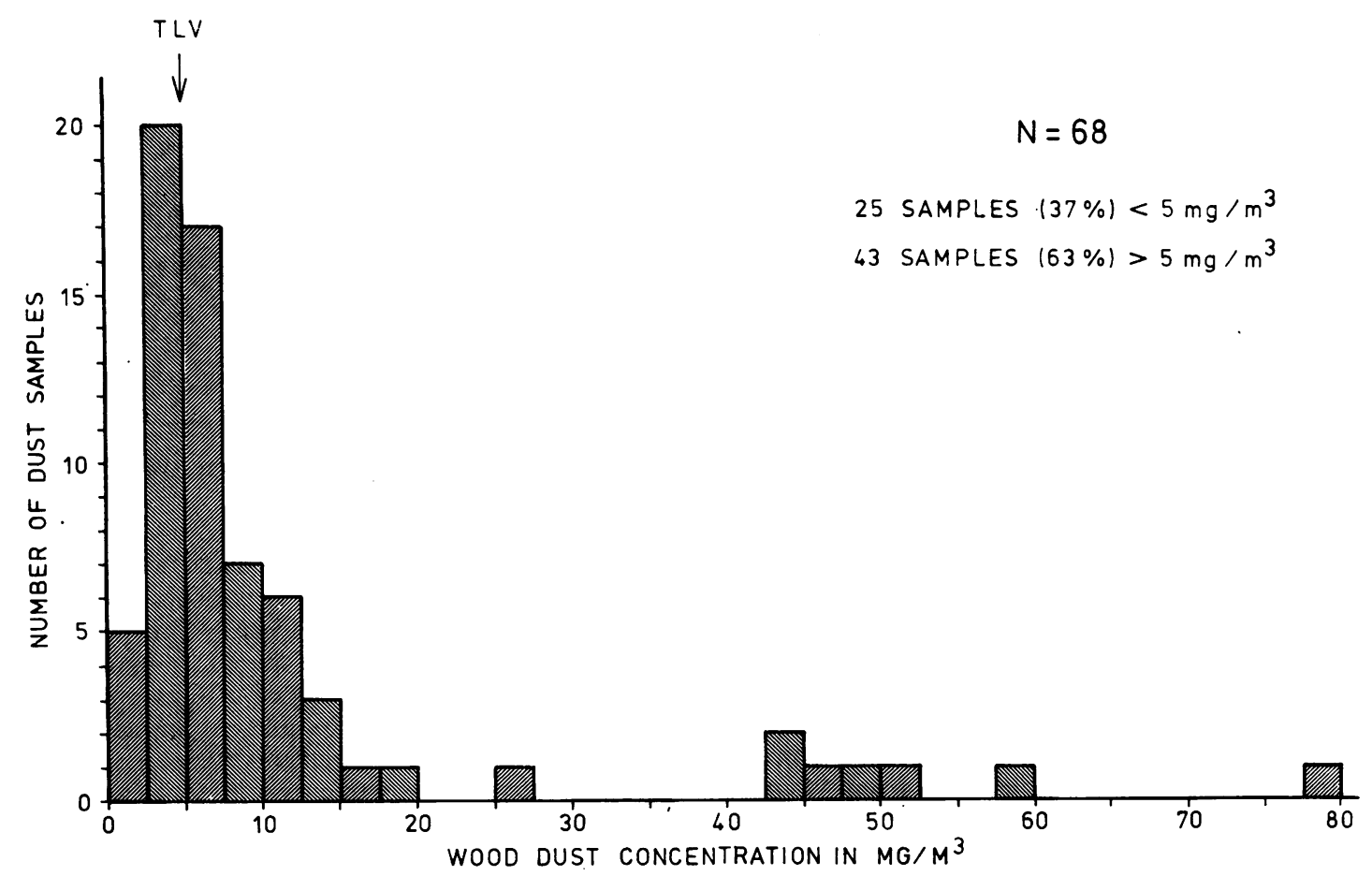

Fig. 2 Wood dust concentrations measured in the breathing zone of the workers.

results. Distribution of the particles according to size in the categories below 5, 6-10, 11-15, and above $16 \mu \mathrm{m}$ in diameter was $33,41,11$ and $15 \%$ respectively.

During the measurements 41 workers were occupied with machine- and hand-sanding and 27 with work such as drilling, planing, or sawing. The average dust concentrations in these two groups were 14.3 and $5.2 \mathrm{mg} \mathrm{m}^{-3}$ respectively, which was a statistically significant difference. Teak was the material most frequently processed, followed by oak, chipboard and palisander, but mahogany, jakaranda, beech, ramin, motiné, Masonite and pine were also processed. Thirty-seven workers processed only one material on the day of investigation, but 21 processed two to four different materials that day. The temperature in the workroom was $17-24^{\circ} \mathrm{C}$, the relative humidity $38-63 \%$.

The most frequent complaints were dryness in the nose, eye irritation, nasal obstruction, prolonged colds and frequent headaches. Workers in dust concentrations below and above $5 \mathrm{mg} \mathrm{m}^{-3}$ have been compared, as the two groups ( 25 and 43 workers respectively) had the same age distribution, time of exposure to wood dust, and smoking habits. Inflammation of the middle ear was significantly more frequent among those exposed to the higher dust concetnration. Sinusitis, prolonged colds, asthma and troubles such as itching or bleeding nose, frequent sneezing and nasal obstruction were more prevalent among those exposed to high dust concentrations but the difference was not significant. No connection was found between symptoms and the work performed, time of exposure or age.

The nasal mucociliary transit time for the 68 subjects is shown in Figure 3. The distribution curve had two maxima, one with 26 subjects $(38 \%)$ at a transit time exceeding 40 minutes (defined as mucostasis) and one at a transit time of 14 minutes. The fastest transit time recorded was 6 minutes.

Figure 4 shows the proportion of woodworkers with mucostasis at five different dust levels. It appears that the number of subjects with mucostasis increases in direct proportion to the dust concentration. In the group with the highest wood dust concentration $\left(25.5 \mathrm{mg} \mathrm{m}^{-3}\right) 63 \%$ had mucostasis, whereas this was found in only $11 \%$ at $2.2 \mathrm{mg} \mathrm{m}^{-3}$. If only those in dust concentrations below and above $5 \mathrm{mg} \mathrm{m}^{-3}$ are considered, 20 and $49 \%$ respectively had mucostasis. On average $\mathbf{9 . 2}$ months had passed since the subjects in the first group had a cold, whereas this interval was only 4.8 months in the second group. 


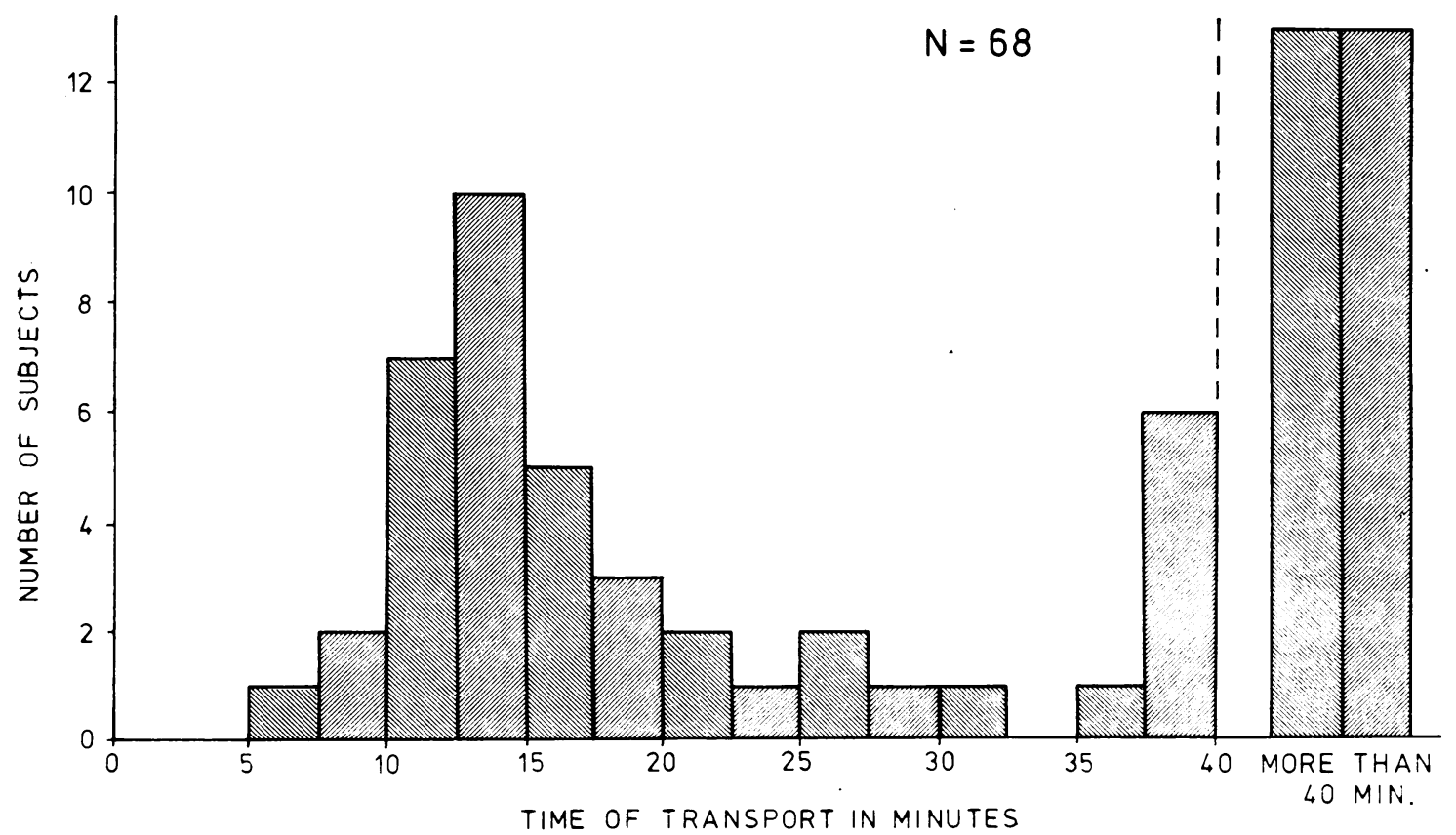

Fig. 3 The distribution of nasal mucociliary transit times measured with the saccharine/sky-blue technique in 68 woodworkers in the furniture industry.

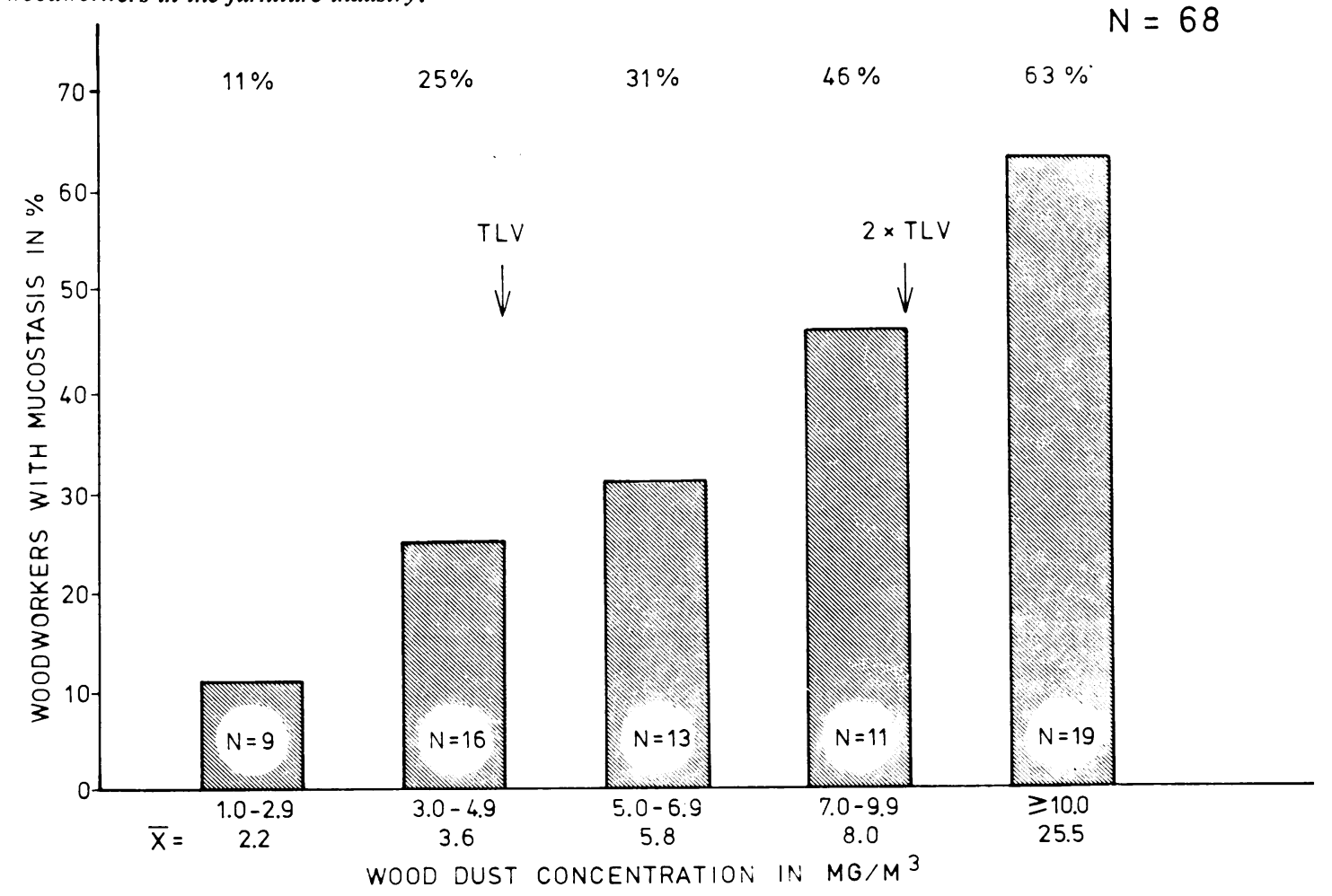

Fig. 4 The proportion of woodworkers in the furniture industry with mucostasis at different wood dust concentrations. 
This difference, which is statistically significant, means that those working at dust concentrations higher than the TLV have more colds than those working at concentrations below the TLV.

Nine subjects with mucostasis were re-examined in their homes at the end of a weekend, that is after 48 hours without wood dust exposure. Three subjects were still mucostatic, whereas six had normal mucus transit times.

The FEV $_{1.0}$ and FEF $_{25-75 \%}$ were compared with theoretical values calculated from the weight and height of the subjects, but no differences were found, nor were there any differences in these measurements in subjects exposed to a high or a low dust concentration.

\section{Discussion}

Adenocarcinoma of the nose is a rare disease with an annual incidence of 0.9 per million in the total population. More than two-thirds of those affected were woodworkers in the furniture industry, making it abundantly clear that this disease is associated with work in the furniture industry.

The risk of adenocarcinoma in cabinet and chairmakers in England has been estimated at $0.7 \pm 0 \cdot 2 / 1000 /$ year during the decade 1956-65, which is at least 500 times the risk incurred by all male adults (Acheson et al., 1968). In the present investigation calculation of an incidence rate is complicated by the difficulty of estimating the population at risk. The latent period is on average 41 years, which means that occupational data from about the year 1930 are relevant. In Denmark an industrial census took place in 1935, and the total number of workers in the furniture industry was then about 6000 (Departement de Statistique, 1940). On the assumption of an even nationwide distribution this indicates that, in the area studied, there were about 2400 woodworkers in the furniture industry and about 4900 woodworkers employed outside the industry in such capacities as carpenters, sawyers, or turners. The woodworkers' trade union has estimated that the number of woodworkers in the furniture industry in the area at that time was about 2500 , which is in very good agreement with the census data. The risk of nasal adenocarcinoma of Danish woodworkers in the furniture industry may then be calculated to be $0.5 / 1000 /$ year, which is comparable to that in England. In the larger group of woodworkers not employed in the furniture industry, there were no cases of nasal adenocarcinoma.

Looking at ectodermal cancers in the nose other than adenocarcinoma it appears that 10 out of 99 tumours in men occurred in woodworkers (Table 1). This is significantly higher than expected from the number of woodworkers in relation to the total male population in 1935 or 1969 . Occupational exposure to wood dust thus may be of importance for the development of other nasal cancers than adenocarcinoma. The predominance of ectodermal tumours in males (males/females: 114/43) in comparison with the sex ratio in the other tumour types (males/ females: 15/14), also supports this hypothesis.

The woodworkers in this investigation were exposed to a wide variety of wood during their working life, and it is not possible to point out potentially carcinogenic types of wood or to estimate the amount of wood dust inhaled.

The wood dust measurements in the modern furniture industries indicate that the risk of nasal adenocarcinoma may still exist, for high wood dust concentrations are often found. Because wood has a mean specific gravity of about 0.8 (beech $0.66-0.83$, oak 0.6-1.03) and a particle size distribution with a maximum of 6-10 $\mu \mathrm{m}$, a substantial amount of the dust will be deposited in the nose. Inert plastic dust with an almost identical size distribution and at a concentration of $25 \mathrm{mg} \mathrm{m}^{-3}$, in five hours does not change the transport rate of human nasal mucus (Andersen et al., in press), for which reason it seems reasonable to exclude the mechanical effect of dust as the cause of the mucostatic effect of wood dust. One rather assumes that the latter is a chemical effect attributable to one or several soluble substances from the wood dust. The constituents of wood are numerous (Kadlec and Hanslian, 1972), and the high temperatures caused by machining operations such as sanding make it possible that the constituents of wood dust differ from and are even more numerous than those of the wood substance itself.

An investigation of nine English furniture workers showed that seven had mucostasis or an extremely slow mucociliary transport rate (less than $1 \mathrm{~mm}$ $\min ^{-1}$ ), and two had a normal transport rate (Black et al., 1974). This observation has been confirmed in the present study where the number of subjects with mucostasis was much higher than that in the population as a whole (Proctor and Andersen, 1976). Further, it appears that the number of mucostatic subjects is directly proportional to the wood dust concentration (Fig. 4). The mucostatic effect, however, seems to be transient as six out of nine workers with mucostasis at work had normal transit rates by the end of a weekend. The study does not allow conclusions about the mucostatic properties of different kinds of wood dust which would be of great interest for future specification of their TLV levels. At present all kinds of wood dust have the same TLV of $5 \mathrm{mg} \mathrm{m}^{-3}$, which may be too high in view of the direct correlation between dust 
concentrations below the present TLV and the number, albeit small, of mucostatic subjects.

The consequences of impaired nasal mucociliary function are not known, but it may be assumed that it is a factor of importance in susceptibility to airborne disease and airborne noxious substances. This hypothesis is supported by the present study, in which workers at high dust concentrations had more colds than workers at low dust concentrations. It may also be assumed that the mucostatic factor in wood dust is of importance in the development of nasal adenocarcinoma in furniture workers because of the prolonged retention of wood dust in the nasal cavity.

The study was supported by the Danish Science Research Council. The death certificates were obtained from O. Horwitz, MD, of the Danish Institute of Clinical Epidemiology.

\section{References}

Acheson, E. D., Cowdell, R. H., and Jolles, B. (1970). Nasal cancer in the Northamptonshire boot and shoe industry. British Medical Journal, 1, 385-393.

Acheson, E. D., Cowdell, R. H., and Rang, E. (1972). Adenocarcinoma of the nasal cavity and sinuses in England and Wales. British Journal of Industrial Medicine, 29, 21-30.

Acheson, E. D., Cowdell, R. H., Hadfield, E. H., and
MacBeth, R. G. (1968). Nasal cancer in woodworkers in the furniture industry. British Medical Journal, 2, 587-596. Acheson, E. D., Hadfield, E. H., and MacBeth, R. G. (1967). Carcinoma of the nasal cavity and accessory sinuses in woodworkers. Lancet, 1, 311-312.

American Conference of Governmental Industrial Hygienists (1976). Threshold Limit Values for Chemical Substances in Workroom Air, Cincinnati, Ohio, 1976.

Andersen, I., Camner, P., Jensen, P. L., Philipson, K., and Proctor, D. F. (1974). Nasal clearance in monozygotic twins. American Review of Respiratory Diseases, 110, 301-305.

Andersen, I., Jensen, P. L., Proctor, D. F., and Swift, D. (in press).

Black, A., Evans, J. C., Hadfield, E. H., MacBeth, R. G., Morgan, A., and Walsh, A. (1974). Impairment of nasal mucociliary clearance in woodworkers in the furniture industry. British Journal of Industrial Medicine, 31, 10-17.

Debois, J. M. (1969). Tumoren van de neusholte bij houtbewerkers. Tijdschrift voor Geneeskunde, 2, 92-93.

Department de Statistique (1940). Annuaire statistique. Gyldendalske boghandel: Copenhagen.

Gignoux, M., and Bernard, P. (1969). Tumeurs malignes de l'ethmoide chez les travailleurs du bois. Journal Médical de Lyon, 50, 731-736.

Kadlec, K., and Hanslian, L. (1972). Wood. In Encyclopaedia of Occupational Health and Safety. Vol. 2, pp. 1507-1509. International Labour Office: Geneva.

Mosbech, J., and Acheson, E. D. (1971). Nasal cancer in furniture-makers in Denmark. Danish Medical Bulletin, 18, 34-35.

Proctor, D. F., and Andersen, I. (1976). Nasal mucociliary function in normal man. Rhinology, 14, 11-17.

Siegel, S. (1956). Nonparametric statistics, 1st edition. McGraw-Hill: New York. 